\title{
Electricity Consumption and Economic Growth in Jordan: Bounds Testing Cointegration Approach
}

\author{
Al-Abdulrazag A. Bashier \\ Economic Department, King Saud University, AL-Riyadh, KSA
}

doi: 10.19044/esj.2016.v12n1p429 URL:http://dx.doi.org/10.19044/esj.2016.v12n1p429

\begin{abstract}
The objective of this paper is to investigate the short-run and longrun causal relationships between electricity consumption and economic growth in Jordan between 1976 and 2013, utilizing the Autoregressive Distributed Lag (ARDL) model. Estimates revealed the existence of a longrun equilibrium relationship between the said variables. The VECM model results indicated a long-run, bidirectional causality between the two variables as seen from the negative and significant error correction terms. The results of Granger-Causality test within VECM disclosed a bidirectional weak and strong short-run causality between electricity consumptions per capita and economic growth. The estimation results provide a strong support for the feedback hypothesis in Jordan.
\end{abstract}

Keywords: Jordan, ARDL, electricity, causality, consumption, economic growth, Cointegration

\section{Introduction}

The contribution of electricity to economic growth has been the focus of applied works in the last few decades. The concern of electricity consumption is triggered by the increased environmental and climate concern due to global warming and climate change (Menzi, 2014). As a result, the need to reduce electricity consumption in order to reduce pollution has emerged. Furthermore, the world energy consumption has been growing particularly in emerging countries such India and China, who are considered the two most populous countries in the world (Menzi, 2014).

Determining the causality direction between electricity consumption and economic growth has attracted the attention of applied economic research. Yet, the question, whether or not electricity consumption triggers and promotes economic growth, is still a controversial issue among applied and theoretical researchers. Recent studies on the relationship between the two variables have provided mixed results, and hence no consistent causality 
direction has been established up till date. However, this inconsistency is due to differences in data set, different analytical and econometric methods utilized, country (developed or developing country), and model variables (Abosedra et al., 2009; Sheng et al., 2007).

The debate focuses on whether electricity consumption causes economic growth, or vice versa, and whether there exists a bidirectional causality between them, or if there is no relationship between them. This disagreement can be seen from four different empirical views. A mainstream research concludes that there is a unidirectional causality running from electricity consumption to economic growth. A second mainstream research suggests a one-way causality running from economic growth to electricity consumption. Consequently, the third mainstream research supports the existence of bidirectional causality between economic growth and electricity consumption. The fourth mainstream research, known as the "Neutrality Hypothesis," declares that there is no causality in either direction between economic growth and electricity consumption.

However, the importance of the causal direction between the said variables for policy makers stems from implementing energy policy conservation (V.R.G. et al., 2010). Therefore, it is important for policy makers to have a clear understanding of the causal relationship between electricity consumption and economic growth. For example, if it is found that there is a unidirectional causality from economic growth to electricity consumption, it indicates that the country can adopt energy conservation policies to reduce energy consumption without harming the growth process. On the other hand, if it is found that the causality direction runs from electricity consumption, it implies that the country is energy dependent. Hence, the country cannot adopt conservative energy policies, since this would cause detrimental effects on economic growth (Narayan and Smith, 2007). Since the direction of causality has significant policy implications for the government for designing and implementing electricity consumption policies, it is important to ascertain empirically the existence and the direction of causal link between electricity consumption and economic growth in Jordan.

The objective of this paper is to investigate the link between electricity consumption and economic growth in Jordan for the period between 1976 and 2013, utilizing the ARDL approach of cointegration and the error correction model (ECM) to explore the long-run and short-run causality between the variables. Granger-Causality within VECM framework explores the strong and weak short-run causality between the variables via Wald test.

The paper construction is as follows. Section 1 is the introduction. Section 2 reviews the literature related to the subject matter. Section 3 
presents the model specification and data. Section 4 presents and discusses the empirical results of ARDL model estimation. Finally, the conclusion and policy implication completes the paper.

\section{Literature Review on the Electricity-growth Nexus}

The empirical literature available on the causality relationship between economic growth and electricity consumption is enormous. Yet, there is no consensus on the direction of the causation. Empirical literature revealed adverse results on the direction of causation when investigating the relationship on a one country level and cross country panel framework (Mustafa \& Charles, 2015). According to economic literature, the direction of the causal relationship between the electricity consumption and the economic growth can be categorized into four hypothesis (Menzi, 2014; V.G. R et al., 2010; Sheng et al., 2007). The present study concentrates mainly on most recent empirical literature on the subject of the causal direction between economic growth and electricity consumption.

(1) Neutrality Hypothesis indicates that there is no causal relationship between electricity consumption and real GDP. Accordingly, the electricity conservation policies will not affect economic growth. It seems that Neutrality Hypothesis has little support in applied literature. Vikas (2015) disclosed that there is no long-run relationship and also no causal relationship between economic growth and electricity consumption in India. He arrived at this conclusion by employing cointegration approach and Granger Causality method. Omisakin (2008), applying ARDL procedure, found no causal relationship (Neutrality) between electricity consumption and economic growth in Nigeria.

(2) Conservation Hypothesis indicates the existence of a one-way causal relationship running from economic growth to electricity consumption, meaning that economic growth causes the development of the electricity sector. Furthermore, the unidirectional relationship indicates that the country is less dependent on electricity, and investing in electricity sector efficiency will not have an adverse effect on economic growth (Visak, 2015). Hence, electricity conservation policies aimed at reducing electricity consumption will have a minor or zero effect on economic growth. Ghahreman et al. (2015), applying the panel cointegration and ECM method, found that there exists a long-run and short-run unidirectional causality running from economic growth to electricity consumption for OPEC countries. Yi Hu et al. (2015), using panel cointegration analysis and VECM approach, disclosed a short-run unidirectional causality from economic growth to electricity consumption for 37 Chinese industries. Menzi (2014), utilizing (ARDL) model and Granger-Causality within VECM framework, found a short-run and long-run unidirectional causality from economic 
growth to electricity in Swaziland. Mohd et al. (2014), using Cointegration approach and the pairwise Granger-Causality, found a unidirectional causal relationship from economic growth to electricity consumption in Malaysia. Odhiambo (2014), utilizing the ARDL-bound testing approach, revealed the existence of a long-run causality from economic growth to electricity consumption in Democratic Republic of Congo (DRC). Shahbaz and Feridun (2012), using ARDL approach, found a unidirectional causality running from economic growth to electricity consumption in Pakistan. Aitor and Ainhoa (2010), applying Toda and Yamamoto (1995) method and the standard Granger-Causality method within Vector Autoregressive (VAR) framework, found a unidirectional causality running from economic growth to electricity consumption in Spain. Narayan et al. (2010), using panel data for seven different region consisting of 93, showed a unidirectional causality from economic growth to electricity for Middle Eastern countries. Sheng et al. (2007), using single data set and panel data procedure for 10 industrializing and developing Asian countries, showed a unidirectional short-run causality running from economic growth to electricity consumption in the panel data.

(3) Growth Hypothesis implies that electricity consumption plays a vital role in an economic growth process. The theory assumes that a unidirectional causality runs from electricity consumption to economic growth. It also indicates that the economy is electricity dependent. Therefore, a reduction in electricity consumption due to electricity conservationoriented policies may have a detrimental impact on economic growth (Sheng et al., 2007; Vikas, 2015). Danial and Manuel (2015), using the cointegration analysis and Granger-Causality in the VECM framework (IRF), found a unidirectional causality running from electricity consumption to economic growth for Ecuador. Mutafa and Charles (2015), using VAR model and Granger-Causality within VECM framework, found a long-run causal relationship running from electricity to economic growth for Ghana. Yi Hu et al. (2015), using cointegration analysis, disclosed a long-run unidirectional causality running from electricity to economic growth for the Chinese industrial sectors. Davoud et al. (2013), employing the Autoregressive Distributed Lag (ARDL) bounds testing approach, found a negative unidirectional causal effect running from Oil products consumption and electricity to economic growth in Iran. Xiao et al. (2012), using the Vector Error Correction (VECM), found a unidirectional causality running from electricity to economic growth in short-run and long-run for China. Abdur and Khorshed (2010), using Granger-Causality test, indicated a short-run unidirectional causality running from electricity generation to economic growth for Bangladesh. V.G.R et al. (2010), using the bounds testing approach to cointegration and Granger-Causality approach within (VECM) model, revealed a long-run positive impact of electricity on economic growth 
in Malaysia. Abosedra et al. (2009), utilizing the Granger-Causality method within VAR framework, revealed unidirectional causality running from electricity consumption to economic growth in Lebanon. Solarin \& Bello (2008) using the ARDL approach to cointegration, FMOLS model, and DOLS model, showed that there is a long-run causal relationship running from electricity to economic growth in Nigeria. Narayan \& Baljeet (2007), using ARDL bounds testing approach to cointegration, revealed the existence of unidirectional causality running from electricity to economic growth in Fiji. Galip \& Karagol (2005), using Dolado - Lu“tkepohl test within Vector Autoregressive approach in levels and standard Granger-Causality to test for Granger non-causality, revealed a strong evidence for unidirectional causality running from electricity consumption to economic growth in Turkey.

(4) Feedback Hypothesis discloses the existence of a two-way (bidirectional) causal relationship between electricity consumption and economic growth. The theory suggests that economic growth and electricity are complements. The Feedback (bidirectional) theory is supported by empirical research work. Aslan (2014), employing the ARDL bounds testing approach to cointegration and Granger-Causality in VECM framework, revealed the existence of a long-run bi-directional causality between economic growth and electricity consumption in Turkey. Bilal (2014), investigating the causal relationship between economic growth and three kinds of electricity namely residential, industrial, and others in Turkey by using Granger causality and VAR model, revealed a bidirectional causal relationship between said variables. Fateh and Tares (2013), using multivariate cointegration approach and Granger-Causality within the VECM framework, found a short-run and long-run bidirectional causality between economic growth and electricity consumption in Algeria. For Cote d'Ivoire, Auguste (2011), utilizing the Autoregressive Distributed Lagged (ARDL) bounds testing approach to cointegration and Granger Causality within VECM framework, disclosed a long-run bi-directional causality between electricity consumption and economic growth. Shahbaz, et al., (2011), using the ARDL bounds testing approach to cointegration and the Granger Causality in the VECM framework for Portugal, indicated a longrun bidirectional causal relationship between the said variables. Idrissa (2010) found a positive bidirectional relationship in the long-run and shortrun between electricity consumption and economic growth for Burkina Faso by applying the ARDL bounds testing approach to cointegration and Granger-Causality within the VECM framework. Theodoros \& Nicoletta (2007) found a bi-directional long run and strong short-run causality between electricity consumption and income for the residential sector in Cyprus using 
annual data covering the period between 1964 and 2004. He achieved this by employing cointegration analysis, VECM, and Granger-Causality.

\section{Model Specification and Data Data and Variables}

The present paper uses annual time series on $\mathrm{GDP}_{t}$ and $\mathrm{EC}_{\mathrm{t}}$ for Jordan covering the study period. The real GDP per capita (constant 2005 US\$) serves as proxy for the economic growth. $\mathrm{EC}_{t}$ is the electricity power consumption (Kwh per capita). The reasons for transferring data into small values are due to the huge values of these economic variables, and utilizing small values of time series data would induce the process to achieve Stationarity (Bakhet et al., 2014). The annual time series data are obtained from the World Development Indicator (WDI, 2014) published by World Bank at constant prices $(2005=100)$. All variables are expressed in a logarithmic form in order to obtain more stationary behavior and reduce the possibility of the existence of heteroscedasticity and autocorrelation (Bekhet \& Othman, 2014).

\section{Methodology}

The purpose of the present paper is to investigate the long-run and short-run causality relationships between economic growth and electricity consumption per capita in Jordan by applying the Autoregressive Distributed Lagged (ARDL) bound testing approach to cointegration introduced by Pesaran et al. (2001). Thus, the ARDL approach has been widely used recently due to some advantages over other different approach to cointegration such as Johansen cointegration approach. Taiwo and Sylvanus (2012) offered three advantages of ARDL. First, this procedure does not require the pre-testing mandated for unit root test to verify that all variables are integrated in the same order as required by Johansen \& Juselius (1988, 1990) and Engle-Granger test (1987). Hence, the bounds testing approach to cointegration can be applied regardless of the integrated order of the independent variables whether they are I(0) or I(1). Note, this does not apply if they are I(2) (Pesaran and Shin, 1999). The second advantage is that the bound test procedure has been proven to have superior performance when compared to other procedures of cointegration and has been widely used in small sample studies. Thirdly, this procedure makes it possible to address the possible endogeniety problem that exists in empirical studies. Furthermore, Persaran and Smith (1999) argued that appropriate modification of the order of ARDL is sufficient to simultaneously correct for the problem of serial correlation and endogeniety (for More on ARDL advantages, see Janish, 2013; Davoud et al., 2013; Odbiambo, 2011). 
The ARDL model for the standard log-linear functional specification of the long-run causality between electricity consumption and real GDP is as follows:

$$
\begin{gathered}
\Delta R G D P_{t}=\alpha_{0}+\sum_{i=1}^{p} \alpha_{1 i} \Delta R G D P_{t-i}+\sum_{i=0}^{q} \alpha_{2 i} \Delta E C_{t-i}+\alpha_{4} E C_{t-1}+\alpha_{5} R G D P_{t-1}+\varepsilon_{t} \\
\Delta E C_{t}=\beta_{0}+\sum_{i=0}^{p} \beta_{1 i} \Delta R G D P_{t-i}+\sum_{i=1}^{q} \beta_{2 i} \Delta E C_{t-i}+\beta_{4} E C_{t-1}+\beta_{5} R G D P_{t-1}+\varepsilon_{t}
\end{gathered}
$$

Where RGDP and EC are the logarithms of RGDP per capita proxy economic growth and electricity consumption per capita respectively. Equations (1) and (2) can also be viewed as an ARDL of order (p, q). The appropriate lags length structure are established by using the minimum Akaike's information criteria (AIC).

The ARDL model involves two steps in order to estimate the longrun relationships between variables. The first step involves investigating the existence of long-run relationships among the variables in the equations under estimation. The literature on ARDL model indicates that the calculated ARDL F-statistic is sensitive to the selection of lag length in the model (Shahbaz et al., 2012; Bahmani et al., 2000). After regression of Equations (1-2), the Wald test (F-statistic) was computed to differentiate the long-run relationship between the concerned variables. The Wald test can be carried out by imposing restrictions on the estimated long-run coefficients of economic growth and electricity consumption. The computed F-statistic value will be evaluated with the critical values tabulated in Table CI (iii) of Pesaran et al. (2001). According to Pesaran et al. (2001), the lower bound critical values assumed that the explanatory variables are integrated at order zero, or I(0), while the upper bound critical values assumed that variables are integrated at order one, I(1). If the computed F-statistic is smaller than the lower bound value, then the null hypothesis is not rejected and we conclude that there is no long-run relationship between electricity consumption and economic growth variables. Conversely, if the computed F-statistic is greater than the upper bound value, then growth-electricity nexus has a long-run relationship. On the other hand, if the computed F-statistic falls between the lower and upper bound values, then the results are inconclusive (Davoud et al., 2013). The Null hypothesis of no cointegration $\left(\mathrm{H}_{0}\right)$ and the alternative hypothesis of cointegration $\left(\mathrm{H}_{1}\right)$ are shown in table 1 as follows:

Table 1.

\begin{tabular}{|c|c||c||c|}
\hline Equation & Null Hypothesis & Alternative & Function \\
\hline \hline Equation 1 & $\alpha_{4}=\alpha_{5}=0$ & $\alpha_{4} \neq \alpha_{5} \neq 0$ & $\mathrm{~F}_{\mathrm{GDP}}(\mathrm{GDP} / \mathrm{EC})$ \\
\hline \hline Equation 2 & $\beta_{4}=\beta_{5}=0$ & $\beta_{4} \neq \beta_{5} \neq 0$ & $\mathrm{~F}_{\mathrm{EC}}(\mathrm{EC} / \mathrm{GDP})$ \\
\hline
\end{tabular}




\section{Non Granger-Causality Test}

If there is evidence of a long-run relationship between variables, the next step is to conduct the standard Granger-Causality augmented with lagged error-correction term. Engle-Granger (1987) suggested that if the Granger-Causality test is conducted at I(1) through VAR framework method, it will be misleading in the presence of cointegration. Therefore, an inclusion of additional variables to the VAR method, such as the error-correction term, would help in exploring the long-run relationship (Shahbaz et al., 2012; Davoud et al., 2013). The causation direction between the underlying variables can be determined by the coefficient of the one lagged errorcorrection term of the long-run effects. Also, the coefficient of the ECM term represents the speed of adjustment back to long-run equilibrium due to a short-run shock. The optimal lag length is selected based on the Akiake Information Criterion (AIC). It should be noted that only cointegrated vectors will be estimated with ECM method (Narayan and Singh, 2007; Odhiambo, 2011; Davoud et al., 2013). In the present study, the GrangerCausality test within VECM model between electricity consumption and economic growth are as follows:

$$
\begin{aligned}
& \Delta R G D P=\beta_{o}+\sum_{i=0}^{p} \beta_{1 i} \Delta R G D P_{t-i}+\sum_{i=1}^{q} \beta_{2 i} \Delta E C_{t-i}+\beta_{4} E C M_{t-1}+\varepsilon_{t} \\
& \Delta E C=\phi_{0}+\sum_{i=0}^{p} \phi_{1 i} \Delta R G D P_{t-i}+\sum_{i=1}^{q} \phi_{2 i} \Delta E C_{t-i}+\phi_{4} E C M_{t-1}+\varepsilon_{t}
\end{aligned}
$$

If there is cointegration among the variables, then there exists a longrun relationship between economic growth and electricity consumption. Hence, it indicates that there is a Granger-Causality in at least one direction, but not the causality between the underlying variables (Shabaz et al., 2012). Therefore, we rely on the F-statistic and the one period lagged errorcorrection term to determine the causality direction. The significance of the F-statistic (or Wald test) on the explanatory variables captures the direction of the short-run causality through the joint test. On the other hand, the tstatistic on the coefficient of the one lagged error-correction term determines the long-run causal effect (Odhiambo, 2011; Shabaz et al., 2012; Menzi, 2014). Applying Non Granger-Causality test to equations (3) and (4), the causality can be examined in three different ways (IIhan \& Ali, 2011) as reported in tables $2 \mathrm{a}-\mathrm{c}$ :

The short-run (weak) causalities can be detected by testing the following hypothesis:

Table 2a.

\begin{tabular}{|c||c||c|}
\hline Equation & Null Hypothesis & Alternative Hypothesis \\
\hline \hline Equation $3 \& 4$ & $\beta_{2}=0$, and $\phi_{1}=0$ & $\beta_{2} \neq 0$, and $\phi_{1} \neq 0$ \\
\hline
\end{tabular}
hypothesis.

The long-run causalities can be detected by testing the following 
Table 2b.

\begin{tabular}{|c||c|c|}
\hline \hline Equation & Null Hypothesis & Alternative Hypothesis \\
\hline \hline Equation $3 \& 4$ & $\beta_{4}=0$, and $\phi_{4}=0$ & $\beta_{4} \neq 0$, and $\phi_{4} \neq 0$ \\
\hline
\end{tabular}

Strong Granger causalities are detected by testing the following hypothesis:

Table 2c.

\begin{tabular}{|c||c|c|}
\hline Equation & Null Hypothesis & Alternative Hypothesis \\
\hline \hline Equation 3 & $\beta_{2}=0$ and $\beta_{4}=0$ & $\beta_{2} \neq 0$, and $\beta_{4} \neq 0$ \\
\hline \hline Equation 4 & $\phi_{1}=0$ and $\phi_{4}=0$ & $\phi_{1} \neq 0 ;$ and $\phi_{4} \neq 0$ \\
\hline
\end{tabular}

\section{Empirical Analysis}

\section{Stationarity test (Unit Root Test)}

Following the spirit of the bounds testing approach to cointegration, there is no need to determine the order of integration of the variables. However, the application of the unit root test is to ensure that no variable is integrated at I(2). Outattara (2004) suggested that the inclusion of any variable at I(2) in cointegration analysis makes the computed F-Statistic for the cointegration meaningless. Pesaran et al. (2001) critical values are based on the assumption that variables should be I(1) or I(0). Therefore, applying the unit root test is still necessary to make sure that none of the variables is integrated at I(2) and beyond (Sahbaz and Feridun, 2012; Yusuf et al., 2011). For unit root test, the Augmented Dickey-Fuller (ADF) is exercised to check the order of integration of model variables, using intercept with/without trend option with automatic AIC lag selection criteria. Table 3 reports the results of the unit root test for stationarity using both the ADF test with intercept only and intercept and trend. It is found according to ADF test that electricity consumption (EC) is integrated at order zero I(0) with intercept only but not with trend and intercept. The economic growth (RGDP) is not stationary at the level in both cases. However, the RGDP becomes integrated at order one I(1). Therefore, it can be inferred that both variables are not integrated at a higher order beyond one I(1). According to Pesaran et al. (2001), the cointegration analysis can be carried out since none of the variables is I(2) or higher.

Table 3. Unit Root Test Results

Augmented Dickey-Fuller (ADF)

\begin{tabular}{|c|c|c|c|c||c|c|c|c|c|}
\hline \multicolumn{1}{|c|}{ Augmented Dickey-Fuller (ADF) } \\
\hline \multicolumn{1}{|c|}{ Level : Intercept only } & \multicolumn{4}{c|}{ Level: Intercept and Trend } \\
\hline Variable & ADF & C.V & Lags & Decision & & ADF & C.V & lags & Decision \\
\hline RGDP & -1.55 & - & 2 & Non- & -1.59 & - & 3 & Non- \\
\hline EC & - & - & 1 & Stationary & - & - & 0 & Non- \\
\hline \multicolumn{7}{|c|}{ First differenced (Intercept only) } & \multicolumn{1}{|c|}{ First differenced (Intercept and Trend) } \\
\hline RGDP & - & - & 2 & Non- & & - & - & 3 & Non- \\
\hline EC & $*$ & $*$ & $*$ & $* *$ & & & & & Non- \\
\hline
\end{tabular}




\section{Bounds Test Approach to Co-integration}

The next step is to explore the existence of long-run relationships between the underlying variables for Jordan's economy using ARDL bounds testing approach to cointegration (Davoud et al., 2013; Narayan \& Singh, 2007). The first step is to determine the optimal lag length. On the first differenced, equations (1) and (2) are selected based on the AIC. The second step is the application of the bounds F-test in equations (1) and (2) to investigate the long-run relationship between variables.

Table 4. Results of Bounds Testing to Cointegration

\begin{tabular}{|c||c||c||c||c||c||}
\hline \hline Dependent Variable & Function & F-Statistics & C.V & $\mathrm{I}(0)$ & $\mathrm{I}(1)$ \\
\hline \hline RGDP & $\mathrm{F}_{\mathrm{RGDP}}(\mathrm{RGDP} / \mathrm{EC})$ & 14.5 & $1 \%$ & 4.81 & 6.02 \\
\hline \hline $\mathrm{EC}$ & $\mathrm{F}_{\mathrm{ENC}}$ (EC/RGDP) & 16.25 & $10 \%$ & 4.81 & 6.02 \\
\hline
\end{tabular}

Table 4 reports the results of ARDL bounds testing to cointegration for both equations (1) and (2). The results indicate that co-integration is present for both equations. This result is supported by the fact that F-static is higher than the upper bound critical value at 1\% critical value. Hence, the null hypothesis of no cointegration for equations (1) and (2) can be rejected. Based on these cointegration results, VECM model will be estimated for both equations.

\section{Long-run Results}

Table 5 reports the results of the estimated ARDL long run coefficient. The results revealed a long-run relationship in both equations. The long-run coefficient of electricity consumption variable is positive and significant, indicating the importance of electricity to economic growth. A $1 \%$ increase in electricity consumption leads to a $1.02 \%$ increase in economic growth. Moreover, RGDP has a positive and significant impact on electricity consumption. In addition, a 1\% increase in economic growth leads to a $0.98 \%$ increase in electricity consumption.

Table 5. Long-run Estimated Results of ARDL $(4,5)$

\begin{tabular}{|c|c|c|}
\hline \multicolumn{3}{|c|}{ Dependent Variable (RGDP) } \\
\hline \hline \multicolumn{1}{|c|}{ Coefficients } & t-ratio \\
\hline \hline EC & 1.021 & $121.88^{*}$ \\
\hline \hline DUM & 0.085 & 0.409 \\
\hline \hline RGDP & Dependent Variable (EC) \\
\hline \hline DUM & 0.988 & $98.69^{*}$ \\
\hline
\end{tabular}

*Significant at $1 \%$ level

\section{Non Granger-Causality Results}

The results of the ECM estimation for the long-run GrangerCausality tests are shown in table 6. The coefficient of ECM when electricity 
is the dependent variable is negative and statistically significant, implying the existence of a long-run causality running from electricity consumption to economic growth. The value of ECM term implies that about $14 \%$ of the disequilibrium in economic growth of the previous year's shock adjusted back to the long run equilibrium in the current year, and it would take about seven years to return back to its long-run equilibrium. As for the electricity consumption function, the ECM term is also negative and statistically significant at $1 \%$ level. This result indicates the existence of a long-run causality running from economic growth to electricity consumption. The magnitude of the ECM term (-0.154) indicates that it would take the economy around 6.7 years to return to its long-run equilibrium. The result provides support to the feedback theory, since there is a long-run bidirectional causality between the said variables.

The existence of a co-integrating relationship between electricity consumption and economic growth in Jordan indicates that there must be a Granger-Causality in at least one direction. Table 5 reports the Wald tests for Non Granger-Causality. It is shown that there is a weak and strong bidirectional short-run causal relationship between electricity and economic growth as indicated by Wald-F test statistic.

Table 6. Non Granger-Causality results, (Wald F-statistic test)

\begin{tabular}{|c|c|c|}
\hline \multicolumn{3}{|c|}{ Equation1 (RGDP) } \\
\hline & Direction & Wald F-statistic \\
\hline $\begin{array}{l}\text { Weak Short-run causality } \\
\end{array}$ & EC to EG & $9.31(0.000)^{*}$ \\
\hline Long-run (ECM) & $\mathrm{EC}$ to $\mathrm{EG}$ & $\begin{array}{c}-0.139(\mathrm{t}=- \\
5.2)^{* *}\end{array}$ \\
\hline "Strong short-run causality & EC to EG & $10.03(0.000)^{*}$ \\
\hline \multicolumn{3}{|c|}{ Equation2 (EC) } \\
\hline "Weak Short-run causality & EG to EC & $15.82(0.000)^{*}$ \\
\hline Long-run (ECM) & EG to EC & $\begin{array}{c}-0.154(\mathrm{t}=- \\
6.1)^{* *}\end{array}$ \\
\hline Strong short-run causality & EG to EC & $13.11(0.000)^{*}$ \\
\hline
\end{tabular}

\section{Stability Test}

The step toward achieving the research objectives is to examine the stability of the long-run parameter of the ARDL model by using the Cumulative Sum (CUSUM) and Cumulative Sum of Square (CUSUMSQ) tests following Pesaran and Pesaran (2001), and Brown et al. (1975). If the plots of these tests statistics stay within the critical bound of $5 \%$ level of significance, the null hypothesis of all coefficients of the regression are stable and cannot be rejected. Therefore, it implies that the coefficients in the error-correction model are stable (Bekhet \& Mater, 2013). As observed in Figures (1) and (2), the plots of CUSUM and CUSUMSQ statistics stay 
within the critical 5\% bound for the period, and hence, the coefficients are stable and they do not suffer from structural break in the cumulative sum.
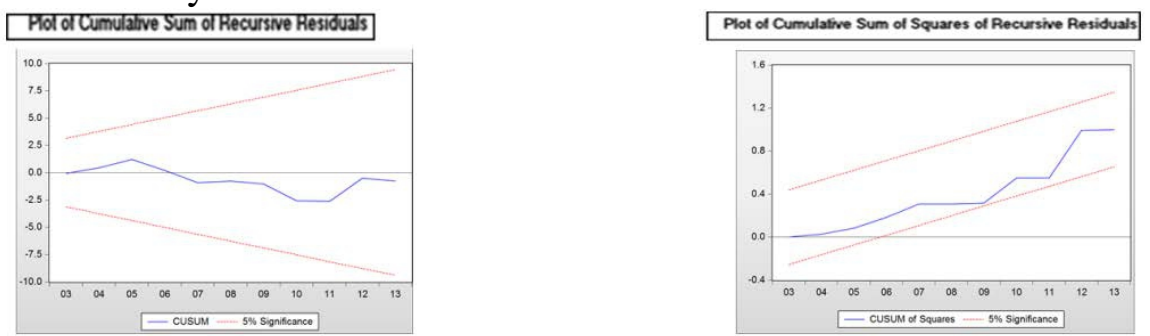

Figure 1. Stability Test for RGDP Equations
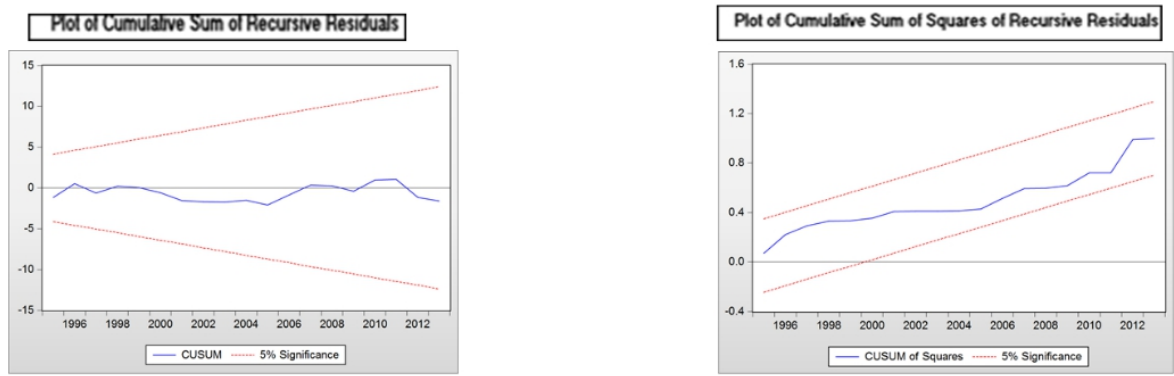

Figure 2. Stability Test for EC Equations

\section{Conclusion}

The goal of the present work was to examine the direction of the causality relationship between economic growth and electricity consumption per capita for Jordan between 1976 and 2013, using the bivariate model. To achieve this goal, Autoregressive Distributed Lag (ARDL) model approach to cointegration was utilized, along with Non Granger-Causality method with VECM framework. The main empirical findings were as follows. First, it is found that there is a long-run equilibrium relationship between the said variables when economic growth and electricity consumption were the dependent variables. Second, the estimates revealed a positive and significant bidirectional impact of electricity consumption on economic growth. Third, Non Granger-Causality test results showed a long-run bidirectional causality between electricity consumption and economic growth as indicated by the negative and significant one period lagged error correction terms supporting the feedback hypothesis for Jordan. Moreover, there were weak and strong, short-run bidirectional causalities between electricity consumption and economic growth. The empirical findings are in line with Aslan (2014) for Turkey, Bilal (2014) for Turkey, Fateh and Tares (2013) for Algeria, Auguste (2011) for Cote d'Ivoire, Shahbaz, et al. (2011) for Portugal, Idrissa (2010) for Burkina Faso, and Theodoros and Nicoletta (2007) for Cyprus. 


\section{References:}

Abdur Rashid Sarker \& Khorshed Alam (2010). Nexus between Electricity Generation and Economic Growth in Bangladesh. Asian Social Science, Vol. 6, No. 12.

Abosedra, Salah, Abdullah Dah, \& Sajal Ghosh (2009). Electricity consumption and economic growth, the case of Lebanon. Applied Energy, 86, 429-43.

Aitor Ciarretaa \& Ainhoa Zarraga (2010). Electricity consumption and economic growth in Spain. Applied Economics Letters, 17.

Auguste K. Kouakou (2011). Economic growth and electricity consumption in Cote d'Ivoire: Evidence from time series analysis. Energy Policy 39, 3638-3644.

Bahmani-Oskooee, M., and Harvey, H. (2006). How sensitive are Malaysia's bilateral trade flows to depreciation? Appl. Econ.38, 1279-1286.

Bekhet, H. A., \& Matar, A. (2013). Co-integration and Causality Analysis between Stock Prices and Their Determinants in Jordan. Economic Modeling, 35, 508-514.

Bilal Kargi (2014). Electricity Consumption and Economic Growth: A LongTerm Co-integrated Analysis for Turkey. International Journal of Economics and Finance; Vol. 6, No. 4.

Brown, R.L., Durbin, J., \& Ewans, J.M. (1975). Techniques for testing the Constance of regression relations overtime. J. Royal Stat. Soc.37, 149-172.

Daniel A. Sanchez-Loor* \& Manuel A. Zambrano-Monserrate (2015). Causality Analysis between Electricity Consumption, Real Gross Domestic Product, Foreign Direct Investment, Human Development and Remittances in Colombia, Ecuador and Mexico. International Journal of Energy Economics and Policy, 5(3), 746-753.

Davoud M., Behrouz S. A., Farshid P., \& Somayeh J. (2013). Oil products Consumption, Electricity Consumption -Economic growth Nexus in the Economy of Iran: A Bounds Testing Co-integration Approach. International Journal of Academic Research in Business and Social Sciences. Vol. 3, No. 1.

Engle, R.F., \& Granger C.W.J. (1987). Cointegration and error correction representation: estimation and testing. Econometrica, 55, 251-76.

Fateh Be'la1 \& Fares Abderrahmani (2013). Electricity consumption and economic growth in Algeria: A multivariate causality analysis in the presence of structural change. Energy Policy 55.

Galip Altinay \& Erdal Karagol (2005). Electricity consumption and economic growth: Evidence from Turkey". Energy Economics 27.

Ghahreman Abdoli, Yazdan Gudarzi Farahani, \& Seyedmasood Dastan (2015). Electricity consumption and economic growth in OPEC countries: a cointegrated panel analysis. OPEC Energy Review. 
Hussain Ali Bekhet \& Nor. Salwati bt Othman (2014). Long-Run Elasticities of Electricity Consumption, FDI, Export and GDP in Malaysia. International Journal of Economics and Finance; Vol. 6, No. 8.

Idrissa M. Ouédraogo (2010). Electricity consumption and economic growth in Burkina Faso: A cointegration analysis. Energy Economics 32.

Janesh Sami (2013). Remittances, Banking Sector Development and Economic Growth in Fiji. International Journal of Economics and Financial Issues Vol. 3, No. 2, pp.503-511.

Johansen, S. (1988). Statistical analysis of cointegrating vectors. Journal of Economic Dynamics and Control, 12, 231-54.

Johansen, S. \& Juselius, K. (1990). Maximum Likelihood estimation and inference on cointegration with applications to the demand for money. Oxford Bulletin of Economics and Statistics, 52, 169-210.

Mario Gómez \& José Carlos Rodríguez (2015). Electricity Consumption and Economic Growth: The Case of Mexico. International Scholarly and Scientific Research \& Innovation 9(8).

Menzi S. Bennett (2014). Electricity Consumption and Economic Growth in Swaziland. International Journal of Recent Research in Interdisciplinary Sciences (IJRRIS), Vol. 1, Issue 2.

Mohd S. S., Nor E. H. \& Mohammad S. I. (2014). Relationship between Energy Consumption and Economic Growth: Empirical Evidence for Malaysia. Business Systems Review, Volume 2, Issue 1.

Mustafa Özer \& Charles Mensah (2015). A Bivariate Causality between Energy Consumption and Economic Growth in Ghana. Proceedings of 7th Annual American Business Research Conference 24 - 23 July 2015, New York, USA.

Narayan K. P., S. Narayan, \& Stephan P. (2010). Does electricity consumption panel Granger cause GDP? A new global evidence. Applied Energy, 87.

Narayan, P.K \& Singh, B. (2007). The electricity consumption and GDP nexus for Fiji Islands. Energy Economics 29.

Odhiambo Nicholas M., (2011). Electricity Consumption, Exports ,and Economic Growth in the Democratic Republic Of Congo: An ARDL-Bounds Testing Approach. The Journal of Developing Areas, Volume 4, No. 48.

Omisakin A. Olusegun (2008). Energy Consumption and Economic Growth in Nigeria: A Bounds Testing Cointegration Approach. Journal of Economic Theory 2 (4): 118-123.

Ouattara, B. (2004). Foreign Aid and Fiscal Policy in Senegal. Mimeo University of Manchester, Manchester.

Ozturk Ilhan \& Ali Acaravci (2011). Electricity consumption and real GDP causality nexus: Evidence from ARDL bounds testing approach for 11 MENA countries. Applied Energy 88, 2885-2892. 
Pesaran, M.H. \& Shin, Y. (1999). An autoregressive distributed lag modeling approach to cointegration analysis. In Econometrics and Economic Theory in the 20 $0^{\text {th }}$ Century: The Ragnar Frisch Centennial Symposium(Ed) S. Storm, Cambridge University Press, Cambridge, pp.36890.

Pesaran MH, Shin Y, \& Smith R. (2001). Bounds testing approaches to the analysis of level relationships. Journal of Applied Econometrics. 16: 289326.

Shahbaz Muhammad \& Mete Feridun (2012). Electricity consumption and economic growth empirical evidence from Pakistan. Qual Quant 46:15831599.

Shahbaz Muhammad, Chor Foon Tang, \& Muhammad Shahbaz Shabbir (2011). Electricity consumption and economic growth nexus in Portugal using cointegration and causality approaches. Energy Policy 39.

Sheng-Tung Chen, Hsiao-I Kuo, \& Chi-Chung Chen (2007). The relationship between GDP and electricity consumption in 10 Asian countries. Energy Policy 35, 2611-2621.

Solarin Sakiru Adebola \& Bello Mufutau Opeyemi (2011). Multivariate Causality Test on Electricity Consumption, Capital, Labour and Economic Growth for Nigeria. Journal of Business \& Economics. Vol. 3 No. 1.

V.G.R. Chandran ,Susan Sharma ,Karunagaran Madhavan (2010). Electricity consumption-growth nexus: The case of Malaysia. Energy Policy 38, 606612.

Vikas Ramesh Adhegaonkar (2015). Energy Consumption and Economic Growth in India: A Causality Analysis. ANVESHAK vol. 4, no. 2.

Xiao Shengfeng, Xu Ming Sheng, Zhu Tianxing, \& Zhang Xuelli (2012). The Relationship between Electricity Consumption and Economic Growth in China. Physics Procedia 24.

Xiaohua Hu \& Xiao Lin (2013). A Study of the Relationship between Electricity Consumption and GDP Growth in Hainan International Tourism Island of China. Research in World Economy, Vol. 4, No. 1.

Yi Hu 1, Dongmei Guo, Mingxi Wang, Xi Zhang, \& Shouyang Wang (2015). "The Relationship between Energy Consumption and Economic Growth: Evidence from China’s Industrial Sectors". Energies, 8, p. 93929406.

Yusuf Umar Dantama, Yahya Z. A., \& Nasiru I. (2012). Energy Consumption-Economic Growth Nexus in Nigeria: An Empirical Assessment Based On ARDL Bound Test Approach. European Scientific Journal; vol. 8, No.12. 